\section{EMBRYARIDDLE}

Aeronautical University

SCHOLARLY COMMONS
Journal of Aviation/Aerospace

Education \& Research

Volume 16

Number 1 JAAER Fall 2006

Article 6

Fall 2006

\title{
Selecting Projects for a Capstone Spacecraft Design Course from Real World Solicitations
}

David B. Spencer

Robert G. Melton

Silvio G. Chianese

Follow this and additional works at: https://commons.erau.edu/jaaer

\section{Scholarly Commons Citation}

Spencer, D. B., Melton, R. G., \& Chianese, S. G. (2006). Selecting Projects for a Capstone Spacecraft Design Course from Real World Solicitations. Journal of Aviation/Aerospace Education \& Research, 16(1). https://doi.org/10.15394/jaaer.2006.1484

This Article is brought to you for free and open access by the Journals at Scholarly Commons. It has been accepted for inclusion in Journal of Aviation/Aerospace Education \& Research by an authorized administrator of Scholarly Commons. For more information, please contact commons@erau.edu. 


\title{
SELECTING PROJECTS FOR A CAPSTONE SPACECRAFT DESIGN COURSE FROM REAL WORLD SOLICITATIONS
}

\author{
David B. Spencer, Robert G. Melton, and Silvio G. Chianese
}

\begin{abstract}
The first decision that goes into setting the tone for a senior capstone spacecraft design course is the choice of the projects. There are several sources of ideas for design projects, including design competitions and topics set by various technical committees. A new source of design ideas comes from real world design projects. The National Aeronautics and Space Administration's Office of Space Science originally released an Announcement of Opportunity in spring 2002 to solicit designs for a complete Mars mission. The Senior Capstone Spacecraft Design course in the Department of Aerospace Engineering at The Pennsylvania State University paralleled this proposal process for the spacecraft design projects for the 2002-2003 academic year. While the original announcement called for proposers to determine what kind of a flight mission they would conduct, eight specific, realistic flight missions were chosen and assigned to the eight teams in the class. Many of the important aspects of the original project were duplicated; however, a significant amount of material was deleted. This paper discusses the outcome of the year-long course, compares some of the designs developed by the students to the designs chosen in the actual NASA mission design, and draws conclusions about the advantages and disadvantages of selecting a project based from a real solicitation.
\end{abstract}

\section{Selecting Projects for a Capstone Spacecraft Design \\ Course from Real World Solicitations \\ When choosing a senior level capstone design} course, many faculty struggle to find projects that both satisfy the goals of the course and provide realistic challenges to motivate the students. According to Debelak (1982), Jakubowski (1994), Phillips (1991), and Dutson (1997), a design project must (1) be challenging, (2) have a high likelihood of being completed in the time allotted, (3) not be too specific that the students cannot find background material, (4) clearly show the connection with theory learned in previous courses, and (5) must provide an opportunity to perform real design work. The last point in giving the students an opportunity to work on a real-world project is the theme of this paper. This paper discusses the selection of senior design projects for the spacecraft design course and outlines the Penn State's Mars Scout 2007 Design Project, a project based on a real spacecraft mission design solicitation from the National Aeronautics and Space Administration (NASA).

A year-long sequence of senior design courses has been taught at Penn State since 1968. At the beginning of each year, a new design project is chosen. Sources of design projects in past years have included the AIAA Student Design competition (2003) and Texas Space Grant Consortium's Marsport (2003) competition. During the 2002-2003 academic year, a new source of design projects was tapped. The design project was chosen to parallel a real-world NASA mission design program. The Mars Scout program (2003) is part of NASA's long-term Mars exploration activities, and it was decided by the authors that the teams in the capstone design course would undertake a modified design project that used the original Mars Scout announcement for the general guidelines in undertaking these projects. This paper discusses the outcome of this course sequence, and compares some of the designs developed by the students to the designs chosen in the real NASA mission design, and draws conclusions about the results of the projects.

Penn State's Mars Scout 2007

NASA's Office of Space Science (OSS) originally released an Announcement of Opportunity (AO) in the 
spring 2002 to solicit reports for Mars Scout investigations. The Mars Scout competition is designed to augment or complement, but not duplicate, major missions being planned as part of NASA's Mars Exploration Program or those under development by foreign space agencies. The selected Scout science mission must be ready for launch before December 31, 2007, with a total mission cost cap of $\$ 325$ million.

While the original AO called for individual proposers to determine what kind of a flight mission they would conduct, eight specific flight missions were chosen and assigned to the eight teams in the class. Many of the important aspects of the original AO were duplicated; however, a significant amount of material was deleted.

The general goals of NASA's Mars Exploration Program (MEP) and its relationship to the investigations solicited through this Announcement of Opportunity (AO) are described in Greeley (Ed., 2001). A more expansive and detailed discussion about the scientific goals and objectives of the MEP is found in the National Research Council report (2002). The overarching goal of this program is to determine whether water currently exists or ever has existed on Mars. Specific missions and individual mission requirements are shown in Table 1.

Table 1

Penn State Mars Scout Missions

\begin{tabular}{|c|c|c|}
\hline Mission Platform & Team Name & Specific Requirements \\
\hline Long-lived rover & MarSci & $\begin{array}{l}\text { The rover must operate for no less than six } \\
\text { months following the first data return }\end{array}$ \\
\hline Long-distance rover & Team Prefontaine & $\begin{array}{l}\text { The rover must be able to cover an area at } \\
\text { least } 5 \text { kilometers from the landing site }\end{array}$ \\
\hline Helicopter & Wop-wop & $\begin{array}{l}\text { The helicopter must be able to cover an area } \\
\text { of at least } 50 \text { kilometers in radius }\end{array}$ \\
\hline Airplane & Mars Airplane & No unique requirements \\
\hline Glider & Mars Glider Design (MGD) & No unique requirements \\
\hline Balloon & Hot Air & No unique requirements \\
\hline Burrowing rover & Penetration & $\begin{array}{l}\text { Must be able to burrow at least } 2-\mathrm{m} \text { below the } \\
\text { Martian surface }\end{array}$ \\
\hline Mars moon sample return & Nemesis & $\begin{array}{l}\text { Must be able to return and retrieve a } 1 \mathrm{~kg} \\
\text { sample to either Low-Earth orbit or on the } \\
\text { Earth's surface. }\end{array}$ \\
\hline
\end{tabular}




\section{Ingredients of the Design Process}

The design process that is employed in this class is documented in Larson and Wertz 1999). Working in teams, the students complete both a preliminary (fall semester) and detailed design (spring semester). This process is inherently multidisciplinary, requiring the use of engineering practices in such subjects as structures, dynamics, electrical and thermal systems, propulsion, controls, and information systems. In addition to the technical design content, this course seeks to enhance students' skills in verbal and written communications and the team approach tq design, which is widely used in industry and government.

\section{Details of Projects}

During the first semester of the 2002-2003 academic year, there were 52 students divided among eight projects (6-7 students/team). There were six students who participated only in the fall semester (due to graduation in December), so the students who were graduating in December were spread out among six teams. This allowed for a minimal disruption of the process during the second semester. Additionally, a second, unrelated project was offered in the spring semester, so the teams had an opportunity to either finish their initial design or move on to the second project. Two of the Mars missions were selfeliminated (the teams chose to disband and pursue other missions), so the final semester included only six of the original eight projects. A brief description of the initial Mars projects is presented next.

Long-lived rover (Berry et al, 2003)

The selection of the team name, Team Prefontaine, was motivated by the theme of Steve Prefontaine (the first major track athlete to wear Nike products). This fits well with the theme of the requirement of a long-lived rover. The rover was named "Air Triton", and has various features that help with the long-life requirement. Some of these features include four inflatable Kevlar wheels, designed to travel about $2 \mathrm{~km} / \mathrm{hr}$ and support a payload mass over 100 kg. The rover design will employ an independent suspension system and a four-wheel drive system with one electric motor located over each axle. The suspension system and rover platforms will be constructed out of composites to ensure high-strength, low weight, low thermal conduction, and some flexibility to prevent crack development and structural failure. The rover will be equipped with a restoring air pump to replenish air that dissipates from the inflatable wheels during the duration of the mission. For long life, the team decided that a Radioisotope Thermoelectric Generator (RTG) would be used to supply power to the rover. They also chose various instruments, and eliminated several because they did not fall within the objectives of the mission. A schematic of the design is shown in Figure 1.

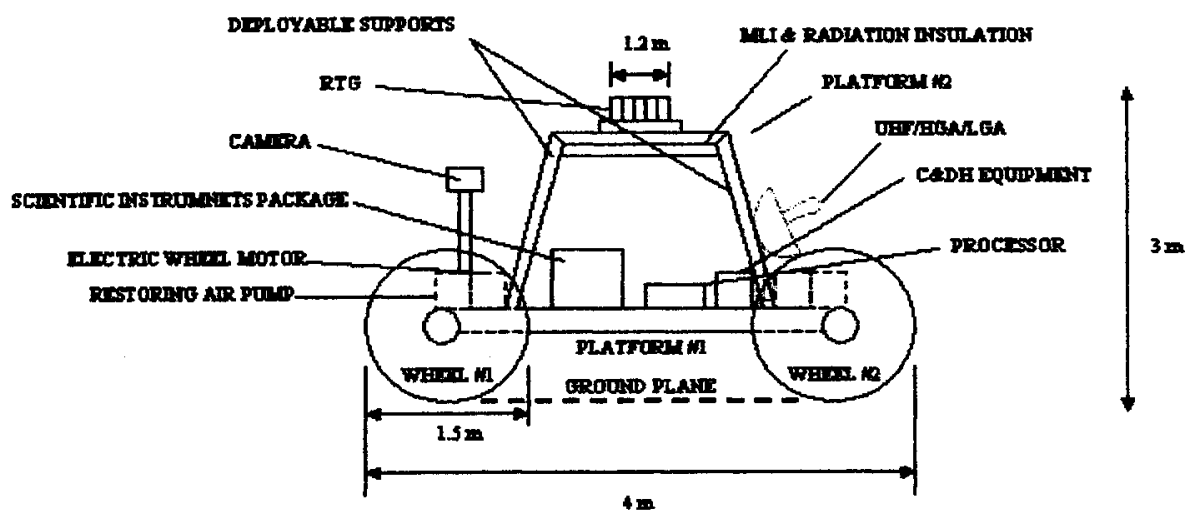

Figure 1. Long-lived Rover (Berry et al, 2003) 
Long-renge rover (Ivarov et al, 2002)

This system will consist of a lander and a semiautonomous rover that will travel at least five kilometers from the lander. There was no requirement on how long this would take, so the team did not have to worry about speed of the rover. The main concern here was to be able to autonomously operate the rover, as it may no longer have line-of-sight visibility from the lander. These vehicles will land on the Martian surface and gather data using temperature and pressure probes, cameras, and a thermal emission spectrometer. The rover will power down all nonvital systems at night in order to conserve power, and recharge the batteries during the day using the solar cells. The rover will be constructed of aluminum and reinforced stainless steel, and will utilize a six-wheeled chassis, with six-wheel drive and four-point turning ability. A picture of the design is shown in Figure 2. This project self-eliminated after the first semester.

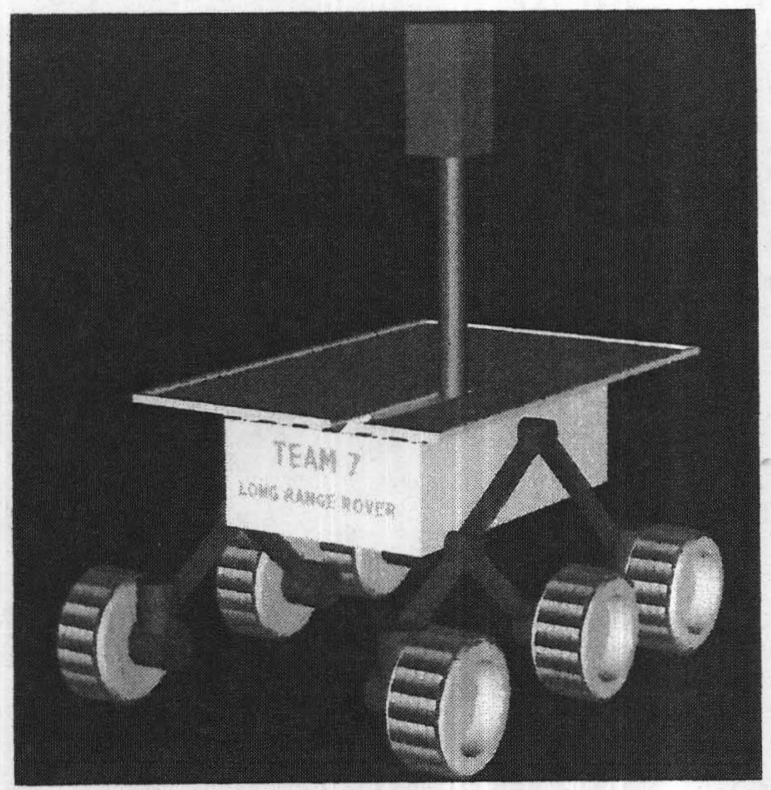

Figure 2. Long Range Rover (Ivanov et al, 2002) 


\section{Helicopter (Jones et al, 2003)}

Team Wop-Wop has designed a helicopter for exploration of Mars. The requirement for the mission is that the helicopter will cover a distance of $50 \mathrm{~km}$. After the spacecraft has entered the Martian atmosphere and before striking the ground, the lander will be released from the spacecraft for entry and the remaining structure will burn up in the atmosphere. Once on the ground the helicopter will begin its mission of searching for evidence of water. Once the helicopter is deployed, the lander will extend a communications tower that will include an antenna to communicate with Earth, a second antenna to communicate with the helicopter, and radar to track the location of the helicopter. A generic design of this helicopter is shown in Figure 3.

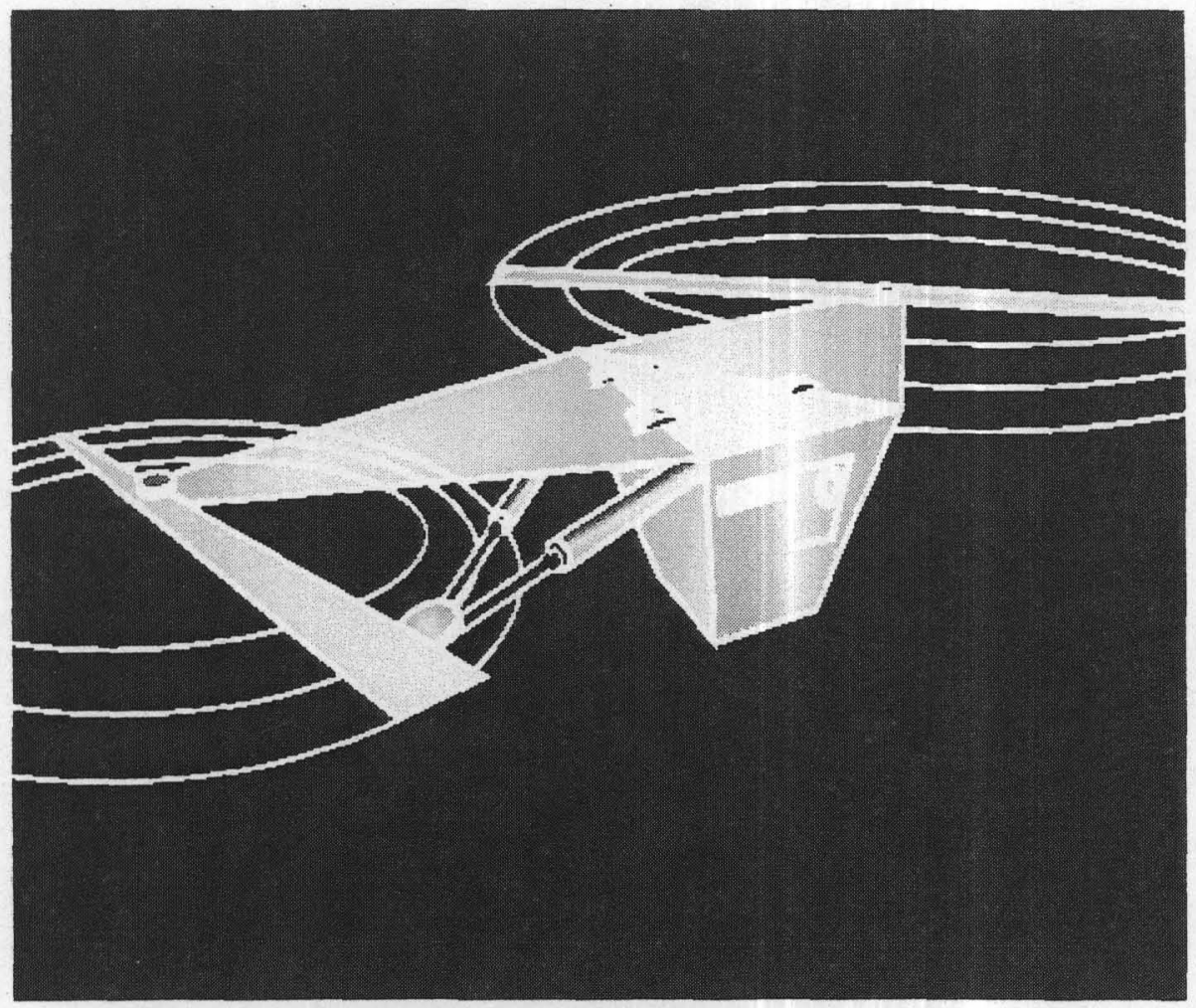

Figure 3. Mars Tandem Rotor Helicopter (Jones et al, 2003) 


\section{Airplane (Creighan et al, 2003)}

The Mars Airplane Mission included inflatable wings, along with rocket propulsion instead of propellers. The wings will be constructed out of a skeleton, which is composed of several inflatable composite tubes. Once in the atmosphere, four retrorocket thrusters will slow the Mars airplane capsule (MAC) to a speed suitable for a parachute deployment. The wings will be inflated immediately upon entry into the Martian atmosphere, using compressed nitrogen as the inflating gas. The wings will be inflated within a fraction of a second as the airplane descends through the atmosphere towards the surface. The inflatable wings will also help slow the airplane down from its initial high velocity when it is ejected from the MAC. Once all the possible data and information are collected, the mission will then be terminated by crashing the airplane into the Martian surface. A drawing of the airplane is shown in Figure 4.

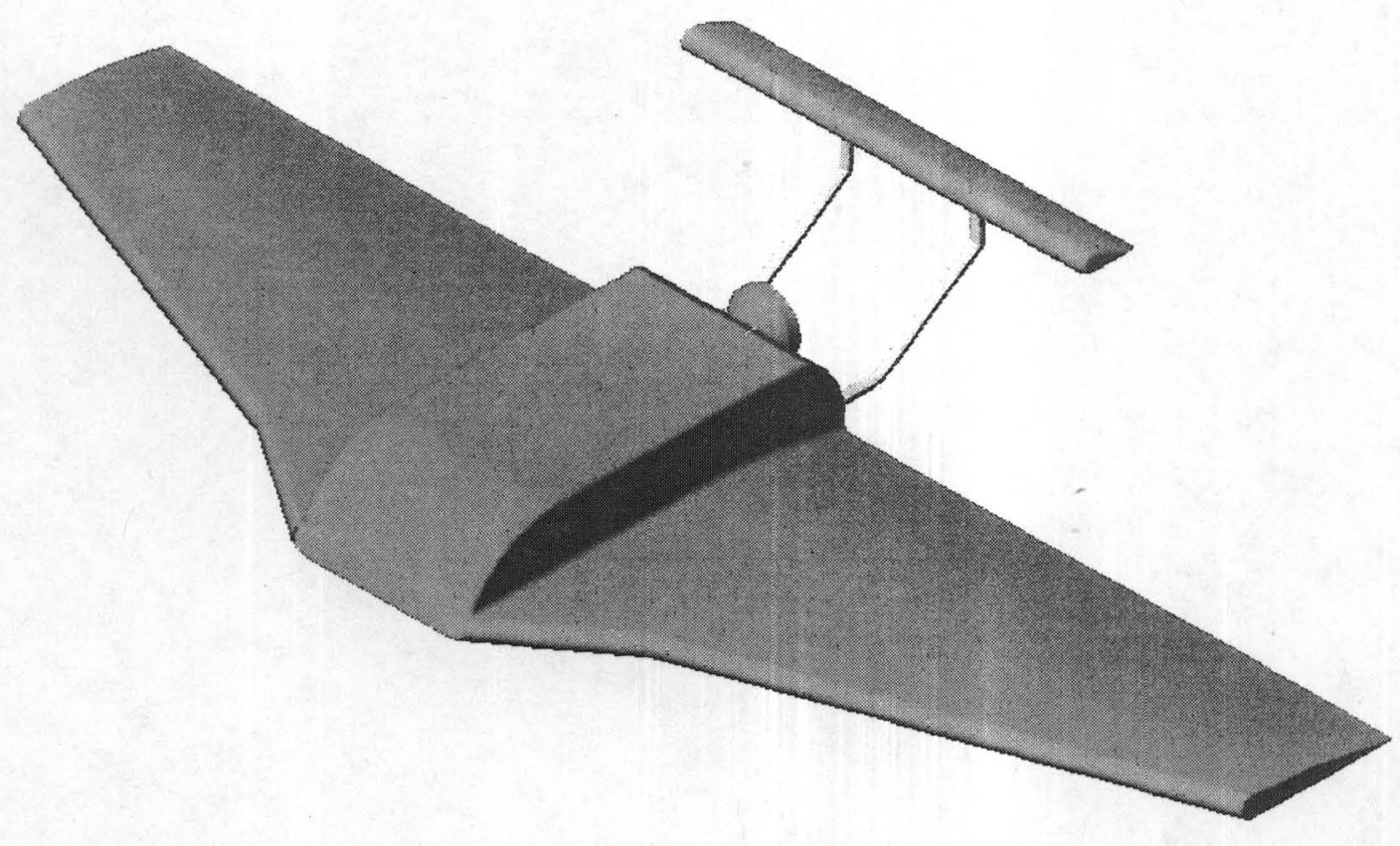

Figure 4. Mars Airplane (Creighan et al, 2003) 


\section{Glider (Bartlett et al, 2003)}

The Mars Deployable Glider (MGD) mission will send a lander (MGD Lite) and a glider, MGD High Life, to Mars to search for evidence of water. The glider will have a rigid wing with a span of 1.8 meters, along with a tail to add

$\rightarrow$ length to the fuselage and provide stability. The large diameter section of the fuselage will support the wing as well as hold all instruments and equipment necessary to complete the mission. This part of the fuselage is attached to a smaller diameter section that connects the tail to the rest of the glider. The glider will be launched from the surface using a small rocket. The rocket will take the glider to an altitude, the glider will deploy its wings, and the glider will cruise around the region until it crashes. The overall mission architecture is shown in Figure 5.

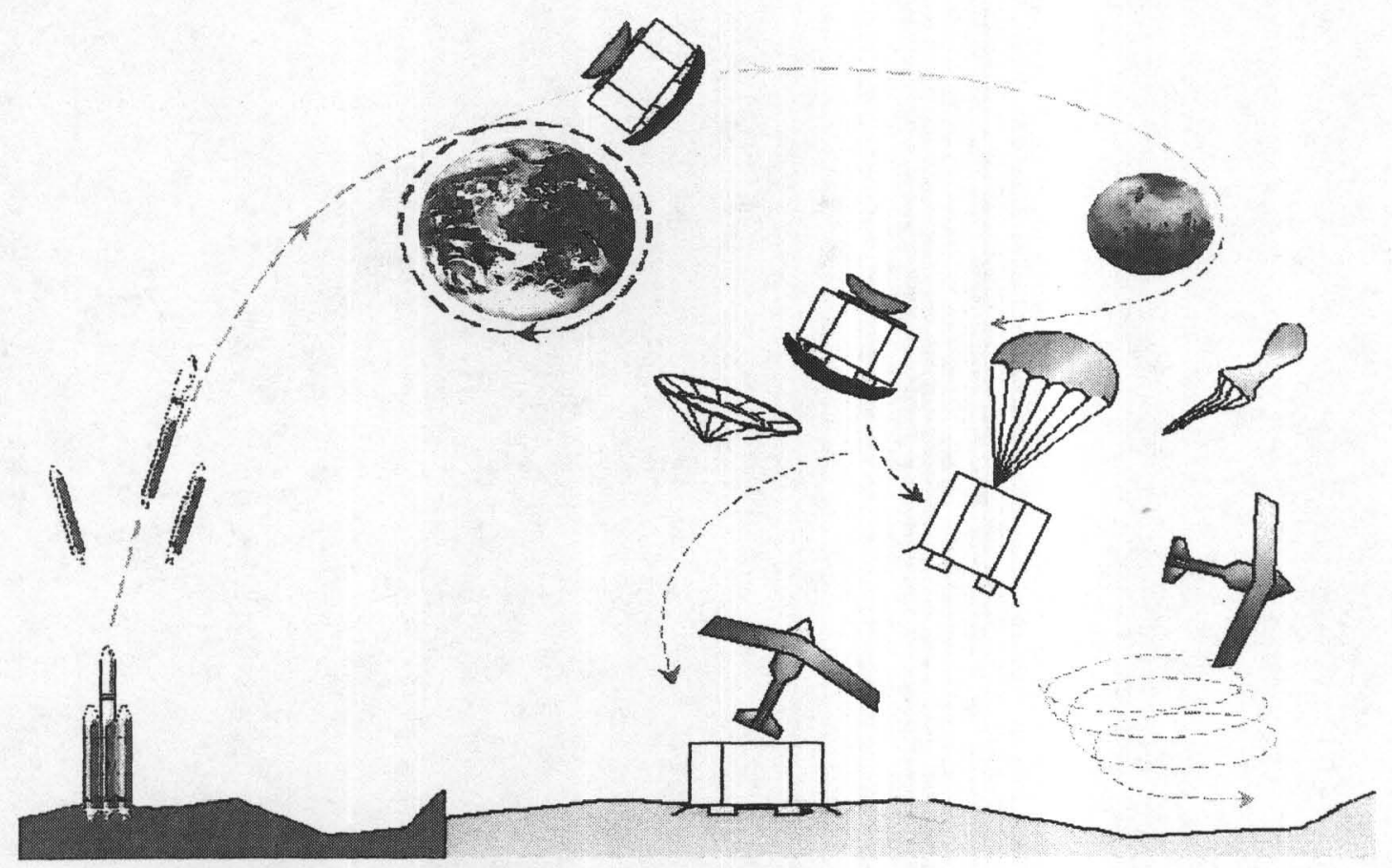

Figure 5. Mars Glider Design Mission Architecture (Bartlett et al, 2003) 


\section{Balloon (Campbell et all, 2002)}

Team Hot Air has proposed using a buoyant balloon and an orbiting satellite, as seen in Figure 6. The overall system includes the balloon, gondola and satellite. The gondola will carry the scientific instruments and will provide added protection from the atmosphere and an RTG. The RTG will be placed at a sufficient distance from the instruments by using a truss structure, and will also be used to warm the carbon dioxide inside the balloon and thus generate lift. The scientific instruments being sent to Mars will all be housed in the gondola of the balloon. These instruments are the Thermal Emission Imaging System, the gamma ray spectrometer, the Martian Radiation Environment Experiment, an onboard thermometer, barometer, and the 2K A VStar camera. The schematic of the balloon designed by the students is shown in Figure 6 . This project was discontinued after the first semester.

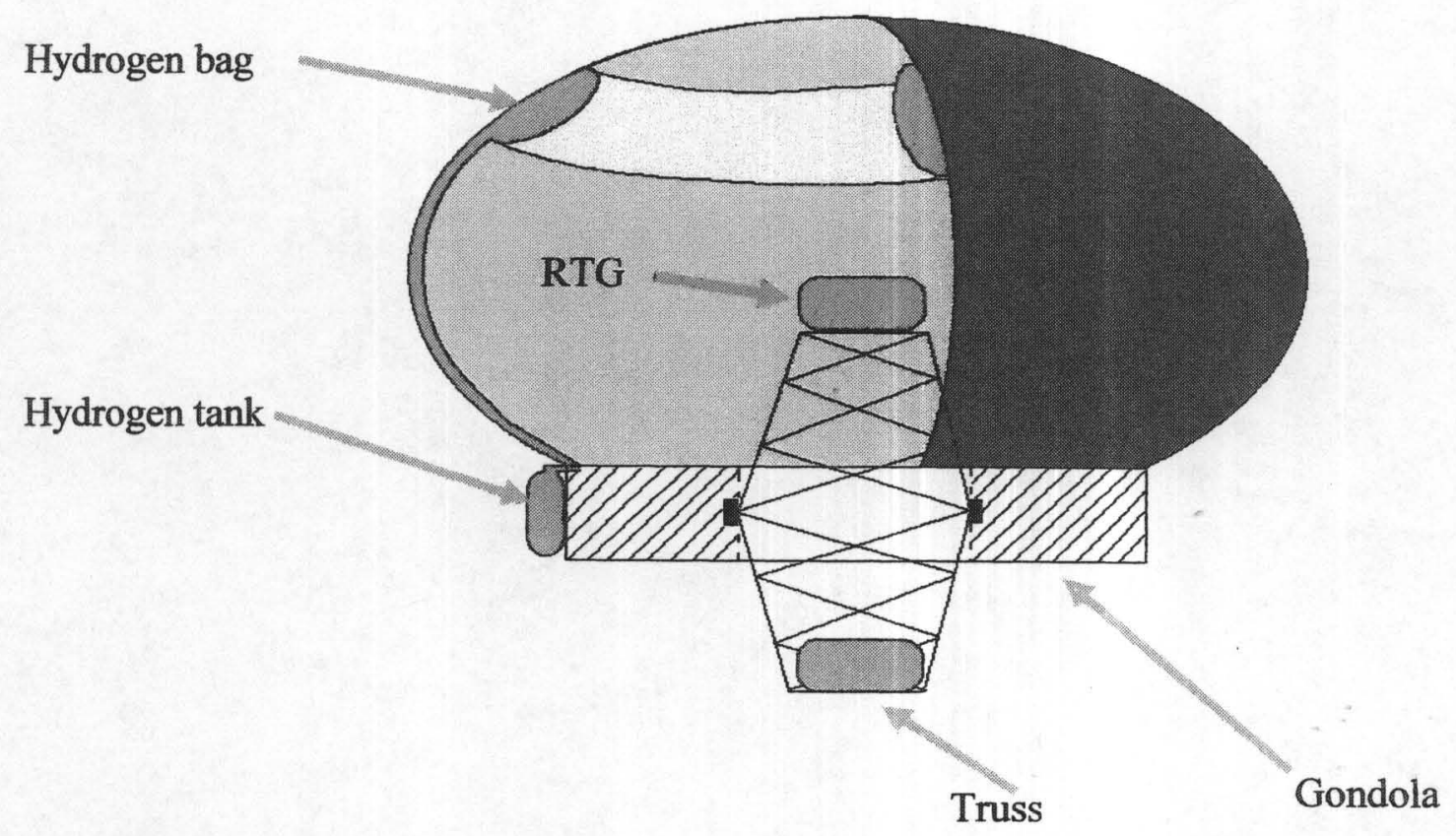

Figure 6. Hot Air Balloon Design (Campbell et al, 2002) 


\section{Burrowing rover (Bergeron ef al, 2003)}

When first proposed, it was anticipated that the burrowing rover would have some sort of drill and burrow down the required 2 meters in depth. Instead, Team Penetration chose to deploy several lance-like penetrators while the lander was parachuting to the ground. These penetrators, similar to the "bunker buster" bombs developed by the military, would be driven into the ground by their kinetic energy from their free fall, and telemeter information back to the lander from sensors located on the penetrators. A mission architecture drawing is shown in Figure 7.

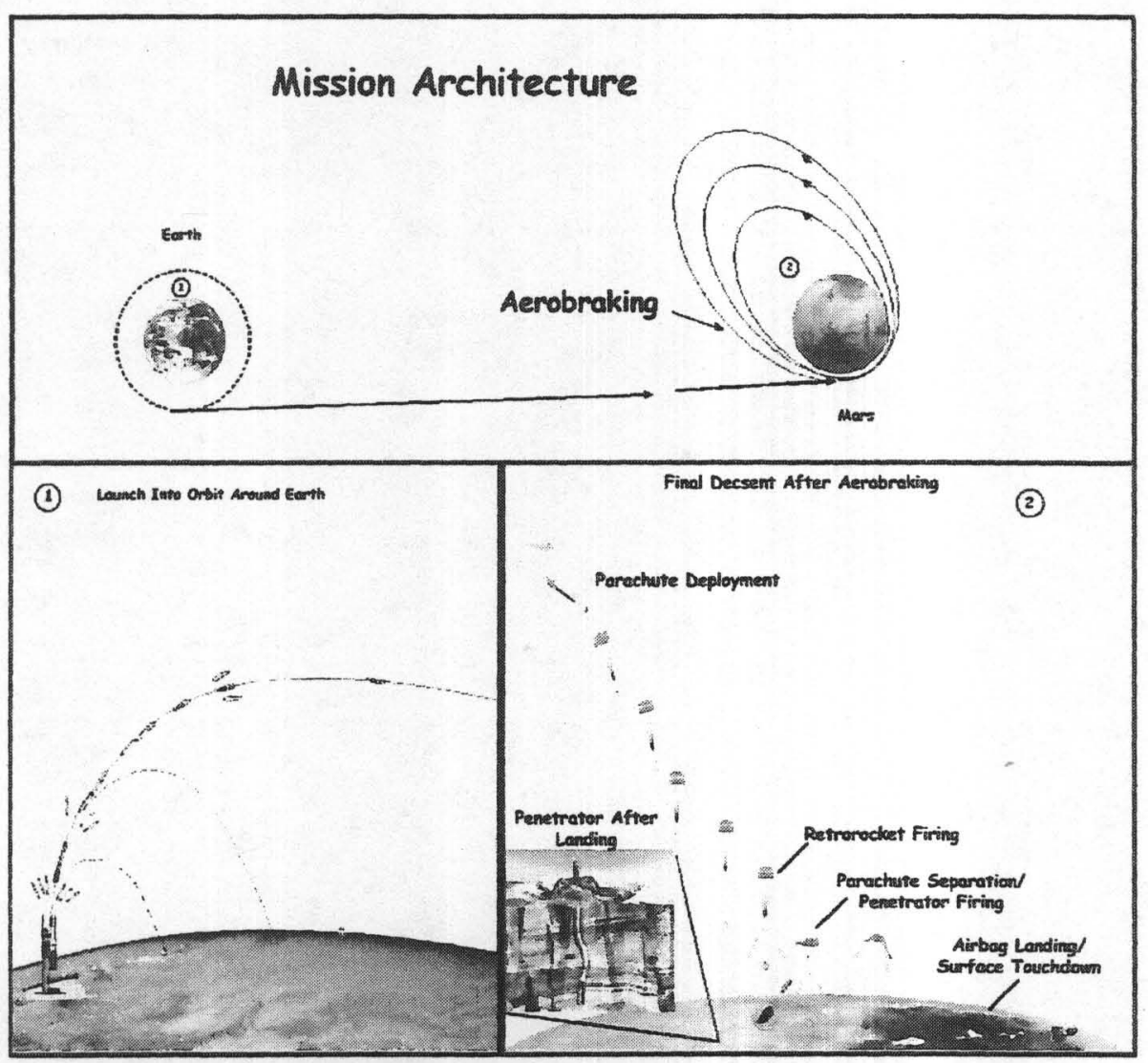

Figure 7. Mission Architecture for Penetration Probes (Bergeron et al, 2003) 
Mars moon sample return (Garland et al, 2003)

The purpose of this mission, as stated in the Announcement of Opportunity, is to pursue the goal of "following the water" on Mars in search for signs of life. Little is known about the moons of Mars: Phobos and Deimos. By studying the composition of Mars' moons it is possible to determine more about the origin of Mars and its composition. The team selected Phobos as the target for the sample return, and the phase of the mission showing the proximity operations of the spacecraft is presented in Figure 8. The primary objective of the Mars Moon Sample Return Mission is to collect a one-kilogram regolith sample from Phobos and return it to low Earth Orbit for scientific investigation.

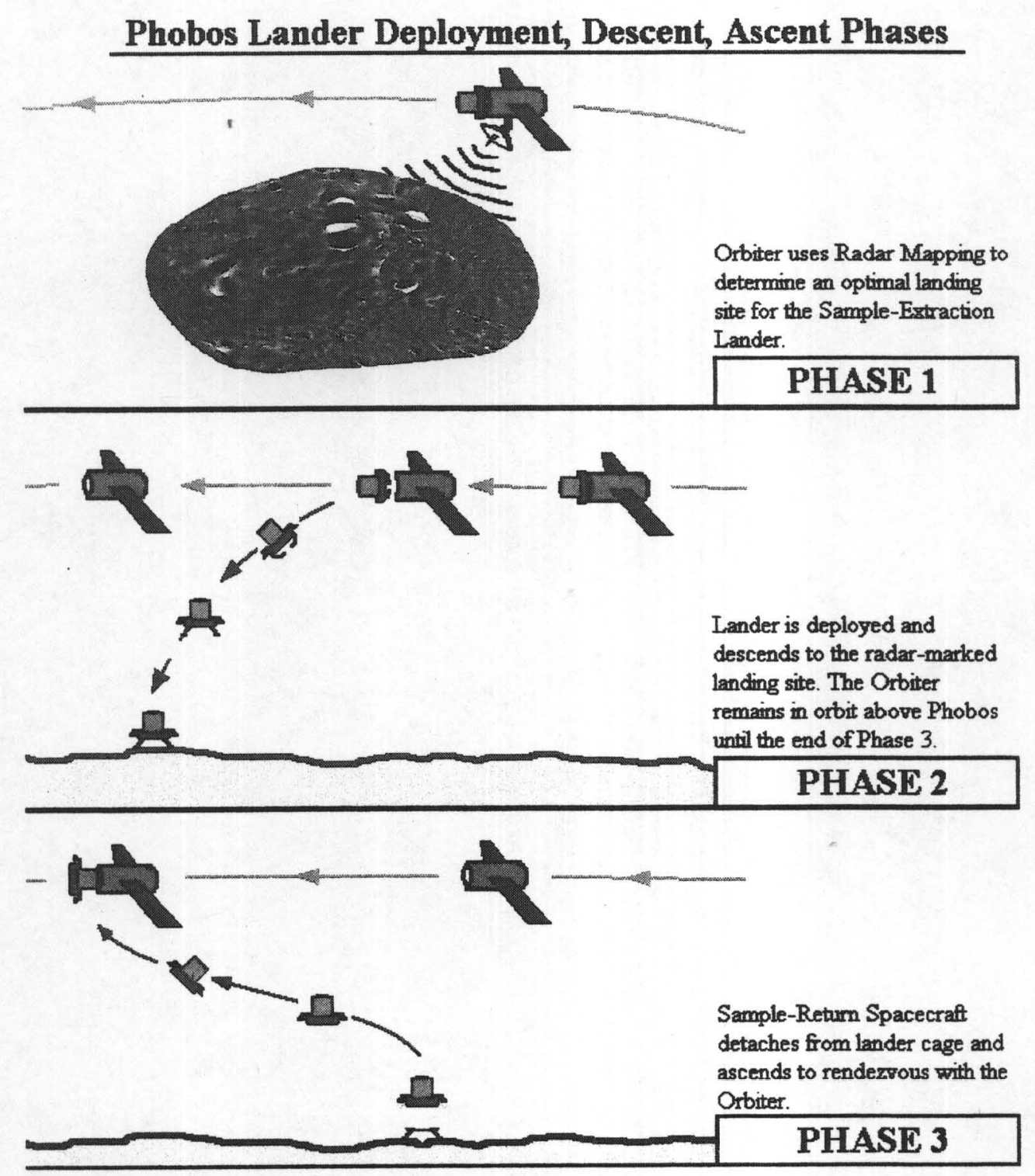

Figure 8. Mars Moon Sample Return Mission Architecture (Garland et al, 2003) 


\section{COMPARISONS WITH REAL MARS SCOUT SELECTIONS}

In December 2002, NASA selected several preliminary proposals to advance into the detailed design phase. Of the four missions selected by NASA to move into the Phase A study, the only one that paralleled one of the projects was the Mars airplane. The Aerial Regional-scale Environmental Survey (ARES) proposal is centered on a NASA Langley aircraft that would fly above Mars returning unique science knowledge about the Mars atmosphere, surface, interior and early climate (NASA Langley Research Center, 2002). The detailed mission-concept studies were due in July 2003, and a final selection for full development of the first Mars Scout mission was made in early August 2003. NASA ultimately selected the Phoenix Mars Lander (Phoenix Mars Lander, 2003) as the 2007 Mars Scout Mission.

While cost was not constrained for the student projects, the real Mars Scout mission was cost-capped at \$325M. The students were asked to estimate costs of their systems using NASA's Spacecraft/Vehicle Level Cost Model (Cost Model, 2003). Generally, their cost estimates ran $50 \%-100 \%$ above the imposed cost-cap. However, much of this can be attributed to the open-ended design options that were left to the students (for example, using an RTG was not ruled out), and the fact that these cost models only provide a rough order-of-magnitude estimate.

\section{STUDENT COMMENTS}

As part of the instructor's feedback, the students in the course were provided with an opportunity to provide written comments on everything related to the course. Overall, the comments were very positive about the selection of the Mars missions as the projects in the course. The students really liked the opportunity to feel like they were working on a real project. When asked what they liked most about the course, students' responses included:

"The creativeness of each group's projects"

"The real life aspect of the projects"

"The projects were based on a real NASA mission" "Content was excellent and strongly related to real world applications"

\section{CONCLUSIONS}

Incorporating these types of missions into a course curriculum has many benefits. The students benefit tremendously by feeling like they are working on is a real mission. They also benefit by being better prepared to enter the workforce and participate on a team developing either a real mission or a real proposal.

Organizations such as NASA can possibly benefit should one or more of the teams generate some very innovative ideas - in this year's design projects, for example, the idea of using lance-like penetrators to burrow down into the surface of Mars was an unpredicted outcome, and a very inventive way of accomplishing the objectives. They also benefit by having graduating students (new employees) who are familiar with the design process and can contribute immediately to a real mission design. $\rightarrow$

David Spencer is an assistant professor and director of graduate studies in the Department of Aerospace Engineering at The Pennsylvania State University. His research areas include: spacecraft dynamics and controls, trajectory optimization, space debris dynamics, and theoretical and applied astrodynamics. He teaches courses in spacecraft dynamics and control and spacecraft design He received a B.S. in Mechanical Engineering from the University of Kentucky, an M.S. in Aeronautics and Astronautics from Purdue University, and a Ph.D. in Aerospace Engineering Sciences from The University of Colorado at Boulder.

Robert Melton is professor and director of undergraduate studies in the Department of Aerospace Engineering at The Pennsylvania State University. His research areas include: satellite dynamics and control, orbital mechanics, and trajectory optimization. He teaches courses in spacecraft dynamics and control and spacecraft design. He received a B.S. in Physics from Wake Forest University, an M.S. in Physics and a Ph.D. in Engineering Physics from The University of Virginia. He is an associate fellow of AIAA, a fellow in AAS, and an Associate Editor for the Journal of Guidance, Control and Dynamics.

Silvio Chianese is a propulsion engineer with Northrop Grumman Space Technology in Redondo Beach, California. He completed his Ph.D. degree in May, 2005 in the Department of Aerospace Engineering at the Pennsylvania State University. He also has a B.S. and M.S. in Aerospace Engineering from Penn State. During the 2002-2003 academic year, he assisted Drs. Melton and Spencer in teaching the spacecraft design course projects that are the subject of this paper. 


\section{ACKNOWLEDGMENTS}

The authors would like to thank Dr. Calina Seybold of NASA/JPL for discussions about the Mars Scout Program. We would also like to commend the students in the 2002-2003 AERSP 401 A/B courses at Penn State for their ingenuity and creativity in making these projects a success. 


\section{REFERENCES}

AIAA Student Design Competition. Retrieved July 24, 2003, from http://www.aiaa.org/education/index.hfm?edu=3

Bartlett, N., Carpenter, C., Johnson, P., Martin, D., \& Navara, D., Mars Glider Design (MGD), Final Report, AERSP 401 B, April $24,2003$.

Bergeron, R, Brettell, P., Bridgen, C., Kalkstein, M., Lopes, L., \& Oechslein, S., Team Penetration, Final Report, AERSP 401 B, April 24, 2003.

Berry, J., Champion, B., Chung, L., Hoffman, R., \& Reichert, E., Air Triton Rover - Team Prefontaine, Final Report, AERSP 401B, April 24, 2003.

Campbell, L., Chadwick III, W., Craychee, T., Garland, D., Haddad, M., Kahn, S., \& Weigle, N., Mars Balloon, Final Report, AERSP 401A, December 9, 2002.

Committee on Planetary and Lunar Exploration, Space Studies Board, Division on Engineering and Physical Sciences, National Research Council. (2002). Assessment of Mars Science and Mission Priorities, Washington, DC: U.S. Government Printing Office.

Creighan, J., Gorman, J., Henry, J., Waggoner, J., \& Weigle, N., Mars Airplane Mission, Final Report, AERSP 401B, April 24, 2003.

Debelak, K.A., \& Roth, J.A. (1982) Chemical Process Design: An Integrated Teaching Approach, Chemical Engineering Education, $16(2), 72-75$.

Dutson, A.J., Todd, R.H., Magleby, S.P., \& Sorensen, C.D. (1997) A Review of Literature on Teaching Engineering Design Through Project-Oriented Capstone Courses, Journal of Engineering Education, 86 (1), 17-28.

Garland, D., Harrison, R., Noonan, E., Mulhollen, B., \&. Szmodis, J., Phoboian Sample Return Team, Final Report, AERSP 401B, April 24, 2003.

Greeley, R, (Ed.). (2001). Mars Exploration Program: Scientific Goals, Objectives, Investigations, and Priorities. Retrieved March 25, 2003, from http://centauri.larc.nasa.gov/mars/MEPAG_MAR_2_2001_GOALS_ETC.pdf

Ivanov, A., Jakub, T., Larson, R, McIntyre, M., Meisenhelder, T., \& Safko, M., Long Distance Land Rover, Final Report, AERSP 401A, December 9, 2002.

Jakubowski, G.S., \& Sechler, R. (1994) SAE Student Design Competitions as Capstone Courses, Proceedings, Advances in Capstone Education Conference, Brigham Young University, 97-101.

Jones, M., Frier, R., Ivanov, A., La Barre, A., \& Shah, N., Mars Helicopter-Team Wop-Wop, Final Report, AERSP 401B, April 24, 2003.

Marsport Student Design Competition. Retrieved July 24, 2003, from http://www.tsgc.utexas.edu

Mars Scout Announcement of Opportunity. Retrieved March 25, 2003, from http://research.hq.nasa.gov/code_s/nra/current/AO-02-OSS-02/main.html 
Mars Scout 2007 Press Release (Phoenix Mars Lander 2007). Retrieved August 4, 2003, from http://nssdc.gsfc.nasa.gov/planetary/text/phoenix_pr_20030804.txt

NASA Langley Research Center press release. Retrieved December 6, 2002, from http://oea.larc.nasa.gov/news_rels/2002/02-090.html\#

NASA's Spacecraft/Vehicle Level Cost Model. Retrieved July 24, 2003, from http://www.jsc.nasa.gov/bu2/SVLCM.html

Phillips, J.R., \& Gilkeson, M.M., Reflections on a Clinical Approach to Engineering Design, Design Theory and Methodology, $31,1-5$.

Wertz, J.R. \& Lawson, W.J. (Eds.). (1999). Space Mission Analysis and Design: $3^{\text {rd }}$ Edition, Microcosm Press, Kluwer Academic Publishers. 